\title{
Family contact, experience of family relationships, and views about family involvement in treatment among VA consumers with serious mental illness
}

\author{
Aaron Murray-Swank, PhD; ${ }^{1-2 *}$ Shirley Glynn, PhD; ${ }^{3-4}$ Amy N. Cohen, PhD ${ }^{5}$ Michelle Sherman, PhD; ${ }^{6-7}$ \\ Deborah P. Medoff, PhD; ${ }^{2}$ Li Juan Fang, MS; ${ }^{2}$ Amy Drapalski, PhD; ${ }^{1-2}$ Lisa B. Dixon, MD, MPH ${ }^{1-2}$ \\ ${ }^{1}$ Department of Veterans Affairs (VA) Capitol Health Care Network (Veterans Integrated Service Network [VISN] 5), \\ Mental Illness Research, Education, and Clinical Center (MIRECC), Baltimore, MD; ${ }^{2}$ Department of Psychiatry, \\ University of Maryland School of Medicine, Baltimore, MD; ${ }^{3}$ Greater Los Angeles Healthcare System at West Los \\ Angeles, Los Angeles, CA; ${ }^{4}$ Department of Psychiatry and Biobehavioral Sciences, University of California, Los \\ Angeles, Los Angeles, CA; ${ }^{5}$ VA Desert Pacific (VISN 22) MIRECC, Los Angeles, CA; ${ }^{6}$ Oklahoma City VA Medical \\ Center, Oklahoma City, OK; ${ }^{7}$ VA South Central (VISN 16) MIRECC, Oklahoma City, OK
}

\begin{abstract}
Family psychoeducation is a highly effective, but underused, evidence-based practice in the treatment of schizophrenia and other serious mental illnesses. This study examined views about family relationships and family participation in care among a sample of 69 consumers with serious mental illness receiving treatment within the Department of Veterans Affairs healthcare system. We found that younger consumers and those with higher levels of psychiatric symptoms were more likely to report family conflict and distress. Of participating consumers, $67 \%$ wanted family participation in their psychiatric treatment and those with at least weekly contact with family were more likely to want family participation. Consumers endorsed a number of barriers to family participation in their mental health treatment, including their own concerns about privacy and burdening family and skepticism that family involvement would be helpful. We discuss implications of these findings for the implementation of evidence-based family programs, including efforts toward development of a novel intervention that will address consumers' concerns and promote effective family participation in care.
\end{abstract}

Key words: evidence-based practice, family burden, family psychoeducation, family services, implementation, patient preferences, quality of care, recovery, rehabilitation, serious mental illness.

\section{INTRODUCTION}

Family psychoeducation (FPE) interventions have been developed to support families coping with the multiple challenges related to the serious mental illness (SMI) of a family member. While various FPE models have been developed, all interventions share numerous core elements, including an empathic, nonblaming stance toward the family; a directive educational focus; and an emphasis on improving family members' communication and problem-solving skills. In a large body of randomized trials, FPE programs lasting 9 months or more have demonstrated robust effects in reducing rates of relapse

Abbreviations: ASI $=$ Addiction Severity Index, BSI $=$ Brief Symptom Inventory, FMPO = Family Member Provider Outreach $($ Program $)$, FPE $=$ family psychoeducation, NAMI $=$ National Alliance for Mental Illness, PORT $=$ Patient Outcomes Research Team, QOL = quality of life, SD = standard deviation, SMI = serious mental illness, VA = Department of Veterans Affairs.

*Address all correspondence to Aaron Murray-Swank, PhD; VA Eastern Colorado Healthcare System, 1055 Clermont Street, Denver, CO 80220; 303-399-8020, ext 2508.

Email: Aaron.Murray-Swank@va.gov

DOI: 10.1682/JRRD.2006.08.0092 
and hospitalization among persons with schizophrenia and have also improved social and vocational functioning [1]. A number of meta-analyses [2-3] and literature reviews $[1,4]$ indicate that FPE is an evidence-based practice and that a growing evidence base supports FPE in the treatment of other psychiatric illnesses, including bipolar disorder [5] and depression [6]. Even more modest levels of family involvement in treatment have been associated with a number of beneficial outcomes, including increased treatment participation [7]; greater satisfaction with care [8]; and improved hope, knowledge, and empowerment among consumers [9]. The Patient Outcomes Research Team (PORT) [10], as well as practice guidelines of the American Psychiatric Association [11] and Department of Veterans Affairs (VA) healthcare system [12], strongly recommend family involvement in treatment as a critical element of quality care for persons with schizophrenia and other SMIs.

Despite this consensus that FPE is an evidence-based practice, quality-of-care studies indicate that such interventions are rarely found in routine service settings for persons with SMI. For example, in a sample of 902 consumers with schizophrenia from the PORT study and a VA extension sample, less than 8 percent of consumers reported that their family attended any kind of educational or support program [13]. Within the VA healthcare system, a recent national survey found that 0 percent of facilities offer FPE programs consistent with evidence-based practice guidelines, 19 percent refer to National Alliance for Mental Illness (NAMI) support programs, and 3 percent refer to another type of family support program [14]. Even minimal family participation in treatment is limited; quality-ofcare studies estimated rates of documented family participation in care at 22 to 45 percent [15-16], with one study finding slightly higher rates in inpatient settings [16].

Theoretical literature has suggested that barriers to the dissemination of family services exist at multiple levels within the mental health service system [17], including system-level factors (e.g., lack of reimbursement or administrative support) and provider barriers (e.g., limited clinician knowledge about the benefit of family involvement, limited clinician skills in working with families, clinician attitude that family involvement will not help). In addition, family members may hesitate to participate in such services or experience practical barriers that limit their ability to attend programs (e.g., transportation difficulties, lack of child care). Finally, consumers of mental health services may have concerns about their family participating in their mental health treatment.
Notably, little empirical data exist on implementation barriers to family participation in treatment among consumers with SMI. Existing studies have focused on barriers to agency adoption of FPE [18] and providers' perceived barriers to implementing such interventions [19]. To our knowledge, no prior studies have directly examined consumers' views of family participation in their mental health treatment and, specifically, what consumers view as barriers to family participation. We designed our study to fill this gap by examining how consumers with SMI experience their family relationships and view family involvement in their clinical care.

One particularly important variable to consider may be the frequency of consumer-family contact, since this may be a primary determinant of how consumers experience their family relationships and think about family involvement in their treatment. A number of studies have documented that most consumers with SMI have regular contact with their family. The PORT survey of 718 consumers with schizophrenia found that 83 percent of consumers had family in their local area and 51 percent had in-person contact with family at least weekly.* Similarly, in a sample of 423 patients with schizophrenia enrolled in a VA cooperative study, 31 percent had daily contact with family while they were in outpatient care, 33 percent had weekly contact, and 36 percent had less than weekly contact [20]. However, prior studies have not examined the relationship between frequency of family contact, consumers' experience of family relationships, and consumers' views about family participation in their treatment.

Frequency of family contact may have important implications for efforts to involve family in treatment. Consumers with more frequent family contact may have family members who are more readily available and interested in meeting with clinicians or attending family programs. Indeed, many studies that established the evidence base for FPE only included participants with high levels of family contact. For example, in an initial major trial of FPE, Falloon et al. only included consumers living (or in close daily contact) with a biological parent [21]. In another key study, McFarlane et al. required that participants be living with their family of origin or have at least

\footnotetext{
*Lehman AF, Steinwachs DM, Fahey M, Patient Outcomes Research Team (PORT). Schizophrenia PORT: Primary data analysis: Analysis of patterns of treatment and outcomes based on primary data. Baltimore (MD): Center for Research on Services for Severe Mental Illness, Johns Hopkins University; 1997. (Unpublished report.)
} 
10 hours of contact a week with participating family members [22]. Relatively little is known about how consumers with less frequent contact with family view family participation in their treatment. For example, such consumers may view family participation in treatment as unnecessary. Alternatively, consumers in less frequent contact with family possibly still value family participation in care, because they may maintain less frequent contact but still be close with family. This issue is particularly important to consider among consumers whose primary family relationships are with siblings and extended family, since level of contact is typically lower in these types of family relationships.

Our study had three primary objectives. First, we sought to characterize patterns of family contact and support among a sample of veterans with SMI receiving mental health care within the VA. In exploratory analyses, we examined whether demographic variables (age, sex, race/ethnicity, education, residence with family) or clinical characteristics (diagnosis, symptoms) were related to consumers' experience of family relationships or family participation in care. Second, we aimed to describe consumers' views about family involvement in their mental health care, including their desire for family involvement, perceived needs for information and services, and barriers to family involvement. Third, we tested the hypotheses that levels of family contact would be associated with a more positive experience of the family environment (higher family satisfaction and support and lower family conflict and distress) and greater desire for family involvement in mental health care.

\section{METHODS}

\section{Study Setting and Sample}

We recruited 69 individuals who had a diagnosis of schizophrenia, schizoaffective disorder, bipolar illness, or recurrent major depression from clinical programs within the VA Maryland Healthcare System. In total, participants were recruited from four clinical programs, including two inpatient units, one partial hospitalization program, and one outpatient mental health clinic. Other inclusion criteria specified that consumers needed to be between 18 and 70 years old and able to consent to research participation. The institutional review boards of the University of Maryland School of Medicine and the VA Maryland Healthcare System approved the study. We obtained a partial waiver of Health Insurance Portability and Accountability Act regulations from the institutional review board for permission to review clinical records before participant consent. This waiver helped us determine whether potential participants in each of the programs would meet diagnostic and age inclusion criteria and therefore be potentially eligible for the study.

Potentially eligible consumers were informed about the study through in-person advertisement (e.g., distribution of information at therapy groups and unit meetings) and posted flyers. To minimize any potential selection bias, we emphasized during recruitment that having family was not necessary for participation in the research. Exact recruitment procedures varied between clinical programs because of differences in program structure, procedures, and feasibility considerations. After general information about the study was distributed in each program, we attempted to individually approach consumers and ask them to participate when possible. In total, we individually contacted 83 consumers to directly invite them to participate in the study. In four cases, the potential participant was determined at the time of contact to be unable to consent to study participation. Of the remaining 79 cases, 10 consumers refused participation, resulting in a participation rate among directly approached consumers of 87 percent.

\section{Assessments and Measures}

Each participant received a complete description of study procedures, provided written informed consent, and then met with research staff for a 60- to 90-minute assessment. Assessment interviews were completed between August 2004 and March 2006. Study participants were reimbursed \$30 upon completion of the interview.

The assessment included a detailed series of questions that identified participants' family support system. Participants were first asked, "Do you have family or others that you consider to be 'like family'?" If they responded affirmatively, they were asked to generate a list of primary individuals in their family support system. For each person identified, participants were asked a series of questions about how far away the identified family member lived, how often they were in contact, and whether they would like that person involved in their mental health treatment. Following these questions, assessors verbally administered standardized measures designed to assess participants' experience of the family environment, their views about family participation in care, as well as demographic and clinical characteristics. The following measures of key variables were included. 


\section{Family Contact}

We adapted a question on family contact from the Brief Quality of Life (QOL) Scale [23] to determine how often participants had in-person contact with each family member in their family support system. For each family member identified, the participant was asked to describe the average level of contact with that person during the past year using one of the following choices: at least daily, at least weekly, at least monthly, less than once a month, or none. In our analyses, we used the highest level of contact with any family member named as a marker of frequency of family contact and created three possible categories of family contact: daily, weekly, and less than weekly.

\section{Family Satisfaction}

Participants completed the subjective family satisfaction scale from the Brief QOL Scale [24], which includes four questions assessing the participants' satisfaction with family relationships. The Brief QOL Scale has been extensively used to assess satisfaction with family relationships among persons with SMI and found to possess adequate reliability and validity [24].

\section{Perceived Support Within Family}

This scale was included in the PORT consumer interview to assess consumers' perceived support and empowerment within the family. The scale was originally part of a NAMI survey of consumers [25]. Participants were read the items and asked whether each statement described what currently happened in their family "a lot" (1), "some" (2), or "not at all” (3). Lower scores indicate more perceived support. Example items include, "You have influence in your family," "You feel that your family really knows what you need," and "You feel that your family accepts you the way you are.”

\section{Family Conflict and Distress}

We used three items from the family module of the Addiction Severity Index (ASI) [26] to measure days of family conflict in the last month, distress about family conflict, and perceived need for family therapy. The family module of the ASI was designed to assess family conflict, perceived family problems, and need for family treatment among persons with substance use disorders and also has been used among persons with psychiatric disorders [27].
Desire for Family Involvement in Mental Health Care

For each identified member of their family support system, participants were asked to respond "yes" or "no" to the question, "Do you want this person involved in your mental health care?" We considered a positive response to involving one family member indicative of a desire for family involvement in treatment.

\section{Family Contact with VA Clinician}

Participants reported the last time one of their family members "met or spoke with a VA clinician who provides your mental health care" using one of the following response choices: during the past month, during the past 6 months, during the past year, more than 1 year ago, or never.

\section{Satisfaction with Services Offered Family}

Participants were asked the degree to which they felt that VA services met their family's needs in the past 3 months; they used one of the following response choices: no family needs have been met (1), a few family needs have been met (2), most family needs have been met (3), and almost all family needs have been met (4).

\section{Family Needs and Barriers Questionnaire}

We developed a set of items to assess participants' perceptions of family needs and perceived barriers to family participation in treatment. In the needs and barriers questionnaire, participants were first asked whether they were willing to consider having family involved in their mental health treatment. Participants who were willing to consider family involvement $(n=52,75 \%$ of the sample) were asked whether they felt their family needed different types of information and services (Table 1). Participants were asked whether they perceived clinician barriers (e.g., clinician does not offer opportunity for family involvement) and family barriers (e.g., no family interest, transportation problems) to having their family involved in their mental health treatment. Additionally, all participants who indicated that they had any family ( $n=67,97 \%$ of the sample) were asked whether they had four specific concerns that would prevent their family from participating in their mental health treatment (e.g., consumer-level barriers such as privacy concerns).

\section{Diagnosis}

We obtained psychiatric diagnoses from a review of the clinical charts. Eligible patients were dichotomized 
Table 1.

Perceived family information needs and service preferences for 52 participants with severe mental illness.

\begin{tabular}{lll}
\hline \multicolumn{1}{c}{ Information or Service } & $\boldsymbol{n}$ & $\mathbf{\%}$ \\
\hline Perceived Information Needs & 42 & 81 \\
Progress in Treatment & 40 & 77 \\
Psychiatric Illness & 40 & 77 \\
Treatment of Illness & 39 & 75 \\
Psychiatric Medications and Side Effects & 38 & 73 \\
Dealing with Psychiatric Emergency & 34 & 65 \\
Planning for Future & 33 & 63 \\
VA Therapy or Treatment Programs & 31 & 60 \\
Veteran's Benefits & 30 & 58 \\
Dealing with Physical Health Problems & 28 & 54 \\
Dealing with Caregiver Stress & 24 & 46 \\
How to Find Psychiatrist/Therapist & 23 & 44 \\
Housing & 23 & 44 \\
Applying for Financial Assistance & 18 & 35 \\
Employment Services & 17 & 33 \\
Substance Abuse Services & & \\
Preferences for Family Services & 33 & 63 \\
Communication Training & 29 & 56 \\
Counseling with Mental Health & 48 \\
$\quad$ Professional & & \\
Family Support Group & & \\
Other Service & & \\
\hline VA = Department of Veterans Affairs. & & \\
\hline \hline
\end{tabular}

into one of two categories. The first category included patients with schizophrenia or schizoaffective disorder. The second category included patients with major affective disorders, including bipolar disorder and recurrent major depression.

\section{Psychiatric Symptoms}

Three subscales from the Brief Symptom Inventory (BSI) were used to assess psychiatric symptoms: depression (six items), paranoid ideation (five items), and psychoticism (five items) [28]. The BSI is a reliable and valid self-report measure of psychiatric symptoms, having been used in a number of psychiatric patient samples. Each item is rated on a 5-point scale, ranging from 0 to 4, that reflects the degree to which the respondent was bothered by each symptom in the prior week. These scales were selected because they reflected the most characteristic symptoms of our sample.

\section{Days Hospitalized}

Participants were asked how many total days they had been hospitalized in the prior year.

\section{Statistical Analysis}

Continuous variables were summarized with mean and standard deviation (SD) values and categorical variables with frequencies. To characterize the sample with respect to family relationships and views about involvement in care, we present descriptive data on family relationships, desire for family involvement in care, and perceived needs and barriers to family involvement. We next assessed whether measures of family functioning and views about family services differed by demographic characteristics (age, race/ethnicity, education, sex), and clinical characteristics (diagnosis, BSI symptom severity). For categorical variables, we used analysis of variance and for continuous variables, we used Pearson correlation coefficients. For the variable of days of family conflict in the past month, we used the Spearman correlation coefficient because of the skewed distribution of this variable.

To determine whether level of family contact was associated with measures of family environment, need for family counseling, and desire for family involvement in care, we derived an index of family contact that was divided into three levels: daily, weekly, and less then weekly. We then tested our hypotheses using chi-square analyses for categorical variables and analysis of variance for continuous variables.

We decided to create three levels of family contact based on both conceptual grounds and the distribution of our data. Conceptually, the cutoff point of weekly contact reflects a general, although imperfect, benchmark for intensity of family involvement, having also been used in a prior report focusing on family contact [20]. Additionally, since we had small numbers of participants with monthly and less than monthly family contact, we decided that collapsing these groups was a better fit for the distribution of our data. We also ran our analyses using four levels of family contact, and the results did not significantly differ.

All statistical tests were two-tailed and used an $\alpha$ level of 0.05 . Given the exploratory purpose of the study, no correction was made for multiple comparisons. 


\section{RESULTS}

\section{Description of Sample}

Table 2 reports the demographic and clinical characteristics of the sample, as well as summary data on family relationships and views about family participation in care. The sample was 84 percent male and had a mean \pm SD age of $49.5 \pm 7.1$ years, reflecting characteristics of the population served by the VA. Sixty-five percent of participants were African American, twenty-five percent were white, and ten percent identified themselves with another racial/ ethnic category. In terms of diagnosis, 75 percent of participants were diagnosed with schizophrenia or schizoaffective disorder and 25 percent were diagnosed with a major affective disorder.

\section{Family Relationships and Environment}

Among the participants, 30 percent reported that they were currently living with family, 41 percent were in daily contact with family, and 81 percent had some family in the local area. The most frequently identified members of participants' family support network were siblings, followed by parents, children, and other relatives (e.g., aunt or uncle, cousin). About one-fifth of the sample (19\%) identified a peer as somebody who was "like family" to them. In terms of satisfaction with family relationships, the mean \pm SD score on the Brief QOL Scale was $3.9 \pm 0.9$ (range = $1-7)$, reflecting an average ranging around the "mixed" point on the response scale. Participants also fell around the midpoint in their rating of support and empowerment within the family, with a mean \pm SD rating of $1.8 \pm 0.5$ (range $=1-3$ ) on the PORT Perceived Family Support scale. Participants reported a mean \pm SD $2.5 \pm 6.4$ days of conflict with family members in the past month and that they were between "slightly" and "moderately" bothered by family problems (mean $\pm \mathrm{SD}=2.3 \pm 1.5$, range $=1-5$ ).

In exploratory analyses, we found that a number of consumer characteristics were associated with perceptions of the family environment. Consumer age was negatively correlated with days of family conflict in the past month ( $r=-0.39, p=0.001$ ) and ratings of severity of family problems $(r=-0.26, p=0.04)$. In terms of symptoms, higher levels of both paranoid $(r=-0.31, p=0.02)$ and psychotic symptoms $(r=-0.31, p=0.01)$ were associated with less satisfaction in family relationships. Higher levels of paranoid symptoms was also associated with less perceived support within the family $(r=0.35, p=0.004)$. Symptom levels were not associated with perceived need for family services or desire for family involvement in treatment.
Table 2.

Characteristics of study participants.

\begin{tabular}{|c|c|c|c|c|}
\hline Characteristics & $N$ & $n$ & $\%$ & Mean \pm SD \\
\hline \multicolumn{5}{|l|}{ Demographic } \\
\hline \multicolumn{5}{|l|}{ Sex* } \\
\hline Male & 69 & 58 & 84 & - \\
\hline Female & 69 & 11 & 16 & - \\
\hline \multicolumn{5}{|l|}{ Race/Ethnicity } \\
\hline White & 69 & 17 & 25 & - \\
\hline African American & 69 & 45 & 65 & - \\
\hline Other & 69 & 7 & 10 & - \\
\hline \multicolumn{5}{|l|}{ Marital Status } \\
\hline Currently Married & 69 & 8 & 12 & - \\
\hline Ever Married & 69 & 36 & 52 & - \\
\hline Never Married & 69 & 33 & 48 & - \\
\hline \multicolumn{5}{|l|}{ Education } \\
\hline$<$ High School & 69 & 12 & 17 & - \\
\hline High School/General Equivalency Diploma & 69 & 28 & 41 & - \\
\hline Some College & 69 & 29 & 42 & - \\
\hline Age (yr) & 69 & - & - & $49.5 \pm 7.1$ \\
\hline \multicolumn{5}{|l|}{ Clinical (range) } \\
\hline \multicolumn{5}{|l|}{ Diagnosis } \\
\hline Schizophrenia/Schizoaffective Disorder & 69 & 52 & 75 & - \\
\hline Major Affective Disorder & 69 & 17 & 25 & - \\
\hline \multicolumn{5}{|l|}{ Current Psychiatric Symptoms } \\
\hline BSI, Depression (0-4) & 69 & - & - & $2.5 \pm 1.1$ \\
\hline BSI, Psychoticism (0-4) & 69 & - & - & $2.4 \pm 0.9$ \\
\hline BSI, Paranoid Ideation (0-4) & 69 & - & - & $2.5 \pm 1.0$ \\
\hline \multicolumn{5}{|l|}{ Treatment Setting } \\
\hline Inpatient & 69 & 19 & 28 & - \\
\hline Outpatient & 69 & 50 & 72 & - \\
\hline Days Hospitalized in Past Year & 65 & - & - & $33.9 \pm 61.7$ \\
\hline \multicolumn{5}{|l|}{ Family Contact and Environment (range) } \\
\hline Has Family or "Familylike” Relationship & 69 & 67 & 97 & - \\
\hline Lives with Family & 69 & 21 & 30 & - \\
\hline Has Family in Local City/County Area & 69 & 56 & 81 & - \\
\hline \multicolumn{5}{|l|}{ Level of Family Contact } \\
\hline Daily & 69 & 28 & 41 & - \\
\hline Weekly & 69 & 18 & 26 & - \\
\hline$<$ Weekly & 69 & 22 & 32 & - \\
\hline \multicolumn{5}{|l|}{ Members of "Family" Support Network } \\
\hline Siblings & 69 & 54 & 78 & - \\
\hline Parents & 69 & 33 & 48 & - \\
\hline Children & 69 & 21 & 30 & - \\
\hline Other Relative & 69 & 19 & 28 & - \\
\hline Peer & 69 & 13 & 19 & - \\
\hline Spouse & 69 & 8 & 12 & - \\
\hline Grandparents & 69 & 2 & 3 & - \\
\hline Family Satisfaction (1-7) & 58 & - & - & $3.9 \pm 0.9$ \\
\hline Perceived Empowerment Within Family (1-3) & 65 & - & - & $1.8 \pm 0.5$ \\
\hline Days of Family Conflict, Past 30 Days (0-30) & 65 & - & - & $2.5 \pm 6.4$ \\
\hline Perceived Family Problems (1-5) & 64 & - & - & $2.3 \pm 1.5$ \\
\hline \multicolumn{5}{|l|}{ Family Participation in Care (range) } \\
\hline Want Any Family Involvement in Care & 69 & 46 & 67 & - \\
\hline Perceived Need for Family Counseling (1-5) & 65 & - & - & $2.9 \pm 1.7$ \\
\hline Any Family Contact with Clinician, Past Year & 69 & 29 & 42 & - \\
\hline Satisfaction with Family-Related Services (1-4) & 56 & - & - & $1.9 \pm 1.1$ \\
\hline $\begin{array}{l}\text { One participant had missing data on this varia } \\
\text { nnsidering all participants. } \\
\text { SI = Brief Symptom Inventory, SD = standard }\end{array}$ & & & 1 & repo \\
\hline
\end{tabular}




\section{Participant Views About Family Participation in Treatment}

Sixty-seven percent of participants $(n=46)$ indicated that they wished to have one or more of their identified family members involved in their mental health care. On the ASI, participants rated family counseling as "moderately" important to them (mean $\pm \mathrm{SD}=2.9 \pm 1.7$, range $=$ $1-5)$. In terms of actual family participation in treatment during the past year, 42 percent of participants reported that a VA clinician had had some telephone or in-person contact with a family member in the past year (Table 2). Inpatient and outpatient groups significantly differed, in that 71 percent of inpatients in our sample reported some clinician-family contact in the prior year compared with only 38 percent of outpatients $\left(\chi^{2}=5.02, p=0.02\right)$. Given the strong effect of service setting on likelihood of clinician-family contact, our further analysis of this variable considered the inpatient and outpatient groups separately. For the question reflecting satisfaction with family-related services, participants reported a mean \pm SD rating of $1.9 \pm 1.1$, corresponding to a response of "only a few of family needs have been met" (Table 2). Data on this item should be interpreted with caution, because several participants indicated that they were unsure, resulting in 13 cases with missing data.

The 52 participants who were willing to consider family involvement were asked what they perceived as their family members' information and service needs. Results are reported in Table 1. On the whole, participants felt that their family would benefit from various types of information, with information directly related to their current psychiatric illness and treatment generally being perceived as most useful. More than half the participants who were willing to involve family felt that communication training and family counseling sessions with an individual clinician would be helpful, and about half believed that a family support group would be useful for their family members.

This subsample of 52 participants was also asked about what they viewed as clinician and family-level barriers to their family's participation in their mental health care. Table 3 reports these results. The most frequently endorsed clinician barriers were a lack of appointment times that fit with families' schedules (29\%) and clinicians not offering the opportunity for family involvement (23\%). Participants also believed that numerous familylevel factors limited family participation in their mental health treatment, with all family barriers except for one being endorsed by 23 to 35 percent of participants in this subsample. African-American participants, as compared with white participants, were more likely to state that family hesitancy to come to a mental health care facility would be a barrier to their family participating in their treatment $\left(\chi^{2}=6.04, p=0.01\right)$. Forty-one percent of African Americans endorsed this as a barrier, whereas 0 percent of white participants endorsed this as a barrier to their family participating in their treatment.

All participants in our sample who could identify family $(n=67)$ were asked if they had concerns that would limit their family's participation in their mental health treatment (Table 3). In terms of consumer-level barriers, 58 percent of participants indicated that they did not want to be a burden to family, about half (49\%) had concerns about their privacy, and a substantial percentage believed that family involvement in their treatment would not help (43\%).

\section{Relationship Between Family Contact, Family Environment, and Participants' Views of Family Involvement in Treatment}

Frequency of family contact was associated with participants' desire to have family involved in their mental health treatment (Table 4). Follow-up individual chisquare comparisons between each group found that

Table 3.

Participants' perceived barriers to family participation in mental health services.

\begin{tabular}{lrr}
\hline \multicolumn{1}{c}{ Barrier } & $\boldsymbol{n}$ & $\mathbf{\%}$ \\
\hline Clinician-Level $(N=52)$ & 15 & 29 \\
Appointment Times Do Not Fit Family Schedule & 12 & 23 \\
Clinicians Do Not Offer Opportunity & 4 & 8 \\
Family Had Bad Past Experience & 4 & 8 \\
Staff Have Not Responded & 3 & 6 \\
Clinicians Discourage Family Contact & & \\
Family-Level $(N=52)$ & 18 & 35 \\
Family Too Busy & 17 & 33 \\
Family Conflict & 15 & 29 \\
No Family Interest & 15 & 29 \\
Family Hesitant to Come to Mental Health Facility & 13 & 25 \\
Transportation & 12 & 23 \\
Family Too Far Away & 9 & 17 \\
Family Too Sick or Frail & & \\
Consumer-Level ( $N$ = 67) & 39 & 58 \\
Concern About Family Burden & 33 & 49 \\
Privacy Concerns & 29 & 43 \\
Do Not Think It Would Help & 18 & 27 \\
Do Not Get Along with Family & & \\
\hline \hline
\end{tabular}


participants in daily $\left(\chi^{2}=7.24, p=0.007\right)$ or weekly $\left(\chi^{2}=\right.$ $4.26, p=0.04)$ contact were more likely to want family involved in treatment compared with the less than weekly group. Our hypotheses that level of family contact would be associated with experience of the family environment were not supported, with one exception. Level of family contact was associated with perceived family problems. Post hoc contrasts found that the participants with weekly contact reported significantly less family distress than those with less than weekly contact $(F=6.67, p=0.01)$. Those with daily contact did not differ from these two groups in their ratings of perceived family problems.

\section{DISCUSSION AND CONCLUSIONS}

This study provides a detailed snapshot of how a sample of VA consumers with SMI experience family relationships and view family participation in their mental health care. Consistent with results from prior studies, we found that most participants in our sample were in regular contact with family [20]. Our study extended prior literature by directly asking participants about their views of family participation in their mental health treatment. We found that a majority of participants wanted family involved in their mental health treatment and greater fre-

*Lehman AF, Steinwachs DM, Fahey M, Patient Outcomes Research Team (PORT). Schizophrenia PORT: Primary data analysis: Analysis of patterns of treatment and outcomes based on primary data. Baltimore (MD): Center for Research on Services for Severe Mental Illness, Johns Hopkins University; 1997. (Unpublished report.) quency of family contact was related to more desire for family participation. However, even the 45 percent of participants with less than weekly family contact expressed a desire for family participation in care. Participants were highly interested in their family receiving specific types of information about their illness and treatment. This finding is consistent with the results of Mueser et al.'s prior study [29], which found that persons with SMI and their family members reported strong needs for information about psychiatric illness and particularly high interest in topics such as medication, side effects, and working with treatment providers.

\section{Implications for Services to Families}

Our findings raise challenges and present opportunities for efforts to implement family-based interventions for consumers with SMI, particularly within the VA. First, we found that participants identified a wide variety of individuals in their family support network. This finding is relevant to the practice of evidence-based models of FPE, since most models were developed for families of origin and typically focused on parents as key participants. As Glynn et al. argue [30], more work is needed to tailor FPE interventions to the diverse range of family situations of consumers with SMI. For example, many participants in our sample identified siblings as key sources of support. While work has extended family interventions to sibling relationships [31], more efforts are needed to understand how to best individualize FPE to the unique family constellations of consumers and families served by such programs.

Table 4.

Level of family contact: Relationship with family environment and desire for family involvement in treatment.

\begin{tabular}{|c|c|c|c|c|c|}
\hline \multirow{2}{*}{ Measure } & \multicolumn{3}{|c|}{ Contact Level (mean \pm SD) } & \multirow{2}{*}{$\boldsymbol{F}$} & \multirow{2}{*}{$\chi^{2}$} \\
\hline & Daily & Weekly & $<$ Weekly & & \\
\hline \multicolumn{6}{|l|}{ Family Environment } \\
\hline Perceived Family Support (1-3) & $1.84 \pm 0.52$ & $1.76 \pm 0.44$ & $1.92 \pm 0.59$ & 0.46 & - \\
\hline Days of Family Conflict in Past Month & $2.71 \pm 7.78$ & $0.76 \pm 2.04$ & $3.60 \pm 6.77$ & 0.40 & - \\
\hline Perceived Need for Family Counseling, ASI (1-5) & $3.11 \pm 1.81$ & $2.50 \pm 1.62$ & $2.95 \pm 1.72$ & 0.69 & - \\
\hline Want Any Family Involvement in Treatment (\%) & 82 & 78 & 45 & - & $8.39^{*}$ \\
\hline
\end{tabular}


Another issue for consideration is diagnostic differences. In our study, we sampled a diagnostically heterogeneous group of consumers to capture views among the full range of consumers in programs serving persons with SMI. While FPE programs have often been developed in more diagnosis-specific ways, issues surrounding family participation in care are relevant across the full spectrum of persons with SMI. One challenge in the "real-world" implementation of family services is determining the degree to which the specific form of family-based services should vary by diagnosis. Unfortunately, our study's relatively small sample size limited meaningful comparison across diagnostic groups.

Importantly, we found that African-American participants were more likely than white participants to report that family hesitancy to come to a mental health facility was a barrier to family participation in treatment. These data suggest that mistrust of mental health services, or perhaps issues of stigma, may significantly limit family participation in treatment among African Americans. This finding is consistent with literature indicating that perceived racism and cultural mistrust are significant factors that may lead to dissatisfaction with healthcare among African Americans [32]. In working with consumers and their families, providers must appreciate these processes that may be barriers to family participation in care and develop culturally sensitive strategies to overcome such barriers.

We also found that participants frequently endorsed a number of concerns about their family participating in their treatment, including worries about burdening family, privacy concerns, and skepticism that family involvement in treatment would help. These data point to a pressing need for clinicians to address consumers' concerns in order to effectively implement services to families. Additionally, consumers may play an important role in engaging their family members to effectively participate in their treatment. If consumers "buy in" to the importance of family involvement and communicate this to family members, families will more likely become engaged as constructive allies in treatment.

Based on these observations about the consumers' role in family involvement, we developed a brief, consumercentered intervention to promote effective family participation in care: the Family Member Provider Outreach (FMPO) Program.* The FMPO intervention is flexible and

\footnotetext{
*Glynn SM, Cohen AN, Dixon LB, Murray-Swank AB. The Family Mem-
} ber Provider Outreach (FMPO) Program. Unpublished treatment manual. individually tailored, while achieving four overarching goals: (1) clarifying the benefits of family participation in treatment for the consumer, (2) enhancing relatives' motivation to participate in treatment, (3) providing consumers and relatives with basic information about psychiatric illness and treatment, and (4) solidifying relatives' relationship with the consumers' treatment team. A combination of motivational, didactic, and behavioral techniques are used in the two-phase, five-to-six-session FMPO intervention, which is currently being further refined and evaluated in an ongoing study.

It is also important to acknowledge that providers' attitudes and behaviors are important determinants of family participation in treatment. In our sample, 23 percent of participants who were willing to consider family participation in care indicated that a lack of invitation from clinicians was a barrier to family participation in their treatment. Prior work has indicated that providers may have various concerns about family involvement in treatment, including how to navigate confidentiality issues [33], as well as workload and other concerns [19]. Addressing these clinician-level barriers is critical to effectively encourage appropriate family involvement in treatment.

\section{Implications for Understanding Family Relationships Among Consumers with Serious Mental Illness}

Our results from the current study also shed light on factors that may influence family functioning among consumers with SMI. Age was inversely related to level of family conflicts and perceived family problems. While our data do not directly identify factors that contribute to this relationship, several potential explanations exist. Younger consumers possibly struggle more with familyrelated issues of autonomy and independence. Rates of substance use, a frequent source of family conflict, may be higher among younger consumers. However, age was not related to desire for family involvement in treatment or perceived need for family services. Thus, older consumers may experience less conflict and family problems yet have other needs that could be addressed through family-based services. Symptom levels were related to various measures of poorer family functioning. While our data do not permit causal inferences, a reciprocal, cyclical relationship may exist between family stress and conflict. Consumers' worsening psychological symptoms could contribute to stress in the family. In turn, family stress may exacerbate the severity of psychological symptoms. 
Alternatively, higher levels of psychological distress and symptoms possibly caused consumers to view their family relationships more negatively.

Our findings should be interpreted in the context of several limitations. A major limitation of the study is the methods by which consumers were sampled. While we attempted to capture a broad range of participants by recruiting across a range of clinical programs (inpatient, outpatient, partial hospitalization), implementing a more comprehensive and representative sampling strategy was not feasible. Our results should be interpreted with this caveat in mind. Moreover, our sample has several characteristics that are important to consider to contextualize the results. Our data reflect the local population and service system, which may not represent the VA population of consumers with SMI or VA mental health programs in general. The consumers in our sample were predominantly male and older than non-VA consumer samples. A majority of our participants was African American, reflecting the demographic characteristics of the study setting. Family relationships and views about family involvement in treatment may vary by consumer age and sex, as well as other characteristics (e.g., rural versus urban, race/ethnicity). Further studies of this topic are needed in different settings with more diverse samples and sophisticated sampling strategies for a better understanding of these issues. Additionally, our sample represents a consumer group that was actively enrolled in treatment. Family relationships and needs are likely to differ in families in which the ill family member is not enrolled in care. Finally, these data only reflect consumers' perceptions of their family relationships and family involvement in care. Other sources of data, such as data obtained from family members, clinicians, and clinical records, would be useful sources of information on these topics. For example, family members themselves may report different views of family relationships, service needs, and barriers. Qualitative methods may be particularly well suited to development of a deeper understanding of consumers' views about family participation in their mental health treatment, as well as the complex array of issues surrounding family participation in the psychiatric care of persons with SMI.

\section{ACKNOWLEDGMENTS}

Dr. Murray-Swank is now with the VA Eastern Colorado Healthcare System in Denver, Colorado.
This material is the result of work supported with resources of the VA Mental Health Quality Enhancement Research Initiative; the Veterans Integrated Service Network 5 Mental Illness Research, Education, and Clinical Center; and the VA Special Fellowship in Advanced Psychology and Psychiatry.

The authors have declared that no competing interests exist.

\section{REFERENCES}

1. McFarlane WR, Dixon L, Lukens E, Lucksted A. Family psychoeducation and schizophrenia: A review of the literature. J Marital Fam Ther. 2003;29(2):223-45. [PMID: 12728780]

2. Pitschel-Walz G, Leucht S, Bäuml J, Kissling W, Engel RR. The effect of family interventions on relapse and rehospitalization in schizophrenia-A meta-analysis. Schizophr Bull. 2001;27(1):73-92. [PMID: 11215551]

3. Pilling S, Bebbington P, Kuipers E, Garety P, Geddes J, Orbach G, Morgan C. Psychological treatments in schizophrenia: I. Meta-analysis of family intervention and cognitive behavior therapy. Psychol Med. 2002;32(5):763-82. [PMID: 12171372]

4. Murray-Swank AB, Dixon L. Family psychoeducation as an evidence-based practice. CNS Spectr. 2004;9(12):905-12. [PMID: 15616476]

5. Miklowitz DJ, George EL, Richards JA, Simoneau TL, Suddath RL. A randomized study of family-focused psychoeducation and pharmacotherapy in the outpatient management of bipolar disorder. Arch Gen Psychiatry. 2003;60(9):904-12. [PMID: 12963672]

6. Emanuels-Zuurveen L, Emmelkamp PM. Spouse-aided therapy with depressed patients. Behav Modif. 1999;21(1): 62-77. [PMID: 8995042]

7. Boyer CA, McAlpine DD, Pottick KJ, Olfson M. Identifying risk factors and key strategies in linkage to outpatient psychiatric care. Am J Psychiatry. 2000;157(10):1592-98. [PMID: 11007712]

8. Prince JD. Family involvement and satisfaction with community mental health care of individuals with schizophrenia. Community Ment Health J. 2005;41(4):419-30. [PMID: 16335351]

9. Resnick SG, Rosenheck RA, Lehman AF. An exploratory analysis of correlates of recovery. Psychiatr Serv. 2004; 55(5):540-47. [PMID: 15128962]

10. Lehman AF, Kreyenbuhl J, Buchanan RW, Dickerson FB, Dixon LB, Goldberg R, Green-Paden LD, Tenhula WN, Boerescu D, Tek C, Sandson N, Steinwachs DM. The Schizophrenia Patient Outcomes Research Team (PORT): 
Updated treatment recommendations 2003. Schizophr Bull. 2004;30(2):193-217. [PMID: 15279040]

11. Lehman AF, Lieberman JA, Dixon LB, McGlashan TH, Miller AL, Perkins DO, Kreyenbuhl J, American Psychiatric Association, Steering Committee on Practice Guidelines. Practice guideline for the treatment of patients with schizophrenia, second edition. Am J Psychiatry. 2004;161 (2 Suppl):1-56. [PMID: 15000267]

12. Office of Quality and Performance Clinical Practice Guidelines [homepage on the Internet]. Washington (DC): Department of Veterans Affairs; c2005-7 [updated 2005 Feb 1; cited 2006 August 7]. Psychoses; [1 screen]. Available from: http://www.oqp.med.va.gov/cpg/PSY/PSY base.htm

13. Resnick SG, Rosenheck RA, Dixon L, Lehman AF. Correlates of family contact with the mental health system: Allocation of a scarce resource. Ment Health Serv Res. 2005; 7(2):113-21. [PMID: 15974157]

14. McCutcheon S. Mental Health QUERI and Family Psychoeducation: The beginning of a translational journey. Minneapolis (MN): VA Midwest Healthcare Network 23 Mental Health Service Line; 2003.

15. Young AS, Sullivan G, Burman MA, Brook RH. Measuring the quality of outpatient treatment for schizophrenia. Arch Gen Psychiatry. 1998;55(7):611-17. [PMID: 9672051]

16. Rosenheck RA, Desai R, Steinwachs D, Lehman A. Benchmarking treatment of schizophrenia: A comparison of service delivery by the national government and by state and local providers. J Nerv Ment Dis. 2000;188(4):209-16. [PMID: 10789997]

17. Sherman MD, Carothers RA. Applying the readiness to change model to implementation of family intervention for serious mental illness. Community Ment Health J. 2005; 41(2):115-27. [PMID: 15974493]

18. McFarlane WR, McNary S, Dixon L, Hornby H, Cimett E. Predictors of dissemination of family psychoeducation in community mental health centers in Maine and Illinois. Psychiatr Serv. 2001;52(7):935-42. [PMID: 11433111]

19. Dixon LB, Lyles A, Scott J, Lehman A, Postrado L, Goldman H, McGlynn E. Services to families of adults with schizophrenia: From treatment recommendations to dissemination. Psychiatr Serv. 1999;50(2):233-38. [PMID: 10030482]

20. Rosenheck RA, Cramer J, Jurgis G, Perlick D, Xu W, Thomas J, Henderson W, Charney D. Clinical and psychopharmacologic factors influencing family burden in refractory schizophrenia. The Department of Veterans Affairs Cooperative Study Group on Clozapine in Refractory Schizophrenia. J Clin Psychiatry. 2000;61(9):671-76. [PMID: 11030488]

21. Falloon IR, Boyd JL, McGill CW, Williamson M, Razani J, Moss HB, Gilderman AM, Simpson GM. Family management in the prevention of morbidity in schizophrenia. Clini- cal outcome of a two-year longitudinal study. Arch Gen Psychiatry. 1985;42(9):887-96. [PMID: 2864032]

22. McFarlane WR, Lukens E, Link B, Dushay R, Deakins SA, Newmark M, Dunne EJ, Horen B, Toran J. Multiple family groups and psychoeducation in the treatment of schizophrenia. Arch Gen Psychiatry. 1995;52(8):679-87. [PMID: 7632121$]$

23. Lehman AF. Evaluating quality of life for persons with severe mental illness: Assessment toolkit. Cambridge (MA): The Evaluation Center at Health Services Research Institute; 1995.

24. Lehman AF. Quality of life issues and assessment among persons with schizophrenia. In: Moscarelli M, Rupp A, Sartorius N. Schizophrenia. Handbook of mental health economics and health policy. Vol. 1. London (England): Wiley; 1996.

25. Uttaro T, Mechanic D. The NAMI consumer survey analysis of unmet needs. National Alliance for the Mentally Ill. Hosp Community Psychiatry. 1994;45(4):372-74. [PMID: 8020925]

26. McLellan AT, Kushner H, Metzger D, Peters R, Smith I, Grissom G, Pettinati H, Argeriou M. The fifth edition of the Addiction Severity Index. J Subst Abuse Treat. 1992;9(3): 199-213. [PMID: 1334156$]$

27. McLellan AT. Guide to the Addiction Severity Index: Background, administration, and field testing results. Rockville (MD): National Institute of Drug Abuse; 1985.

28. Derogatis LR. BSI 18, Brief Symptom Inventory 18: Administration, scoring, and procedures manual. 4th edition. Minneapolis (MN): NCS Pearson; 1993.

29. Mueser KT, Bellack AS, Wade JH, Sayers SL, Rosenthal CK. An assessment of the educational needs of chronic psychiatric patients and their relatives. Br J Psychiatry. 1992; 160:674-80. [PMID: 1591577]

30. Glynn SM, Cohen AN, Dixon LB, Niv N. The potential impact of the recovery movement on family interventions for schizophrenia: Opportunities and obstacles. Schizophr Bull. 2006;32(3):451-63. [PMID: 16525087]

31. Marsh DT. Serious mental illness and the family: The practitioner's guide. New York (NY): Wiley; 1998.

32. Benkert R, Peters RM, Clark R, Keves-Foster K. Effects of perceived racism, cultural mistrust and trust in providers on satisfaction with care. J Natl Med Assoc. 2006;98(9): 1532-40. [PMID: 17019925

33. Marshall T, Solomon P. Professionals' responsibilities in releasing information to families of adults with mental illness. Psychiatr Serv. 2003;54(12):1622-28. [PMID: 14645802]

Submitted for publication August 12, 2006. Accepted in revised form January 29, 2007. 